BLS 35, No 1 2009. DOI: http://dx.doi.org/10.3765/bls.v35i1.3604

(published by the Berkeley Linguistics Society and the Linguistic Society of America)

\title{
Event Structure Integration: Korean -ese Constructions
}

\author{
JISUP HONG \\ University of California, Berkeley
}

\section{Introduction}

The connective verbal suffix -ese is very commonly recognized in Korean as establishing one of two relations between clauses: temporal sequence and forward causality, shown below, respectively:

a. John-i cip-ey ka-se kongpu hay-ss-ta

John-NOM home-LOC go-ESE study do-PST-DEC

'John went home and (then) studied (there).'

b. John-i cip-ey ka-se chulswu-to cip-ey ka-ss-ta

John-NOM home-LOC go-ESE Chulsu-also home-LOC go-PST-DEC

'John went home and so Chulsu went home too.'

Although there is widespread agreement that these senses occur in nearcomplementary distribution-i.e. any particular instance of a $P$-ese $Q$ construction conveys specifically one of the two senses - a descriptively adequate and explanatorily satisfying analysis has proven elusive. In this paper, I present a new approach to the analysis of multi-functional connectives based in Cognitive Grammar (Langacker 1991a), arguing that the phenomena of interest require a cognitively sophisticated semantics for an adequate treatment.

\section{The Difficulty with -ese Constructions}

Korean learning grammars tend to state conditions for the sequential reading such as, "the verb in the first sentence must be an action verb" (Ihm et al. 1988), or that when the subjects are coreferential, the meaning is sequential, otherwise, causal (Lee 1989, Rogers et al. 1992). A more comprehensive characterization is attempted in Lukoff and Nam (1982). The following is a restatement of their generalizations in terms of a $P$-ese $Q$ construction: 


\section{Jisup Hong}

(2) a. If $\mathrm{P}$ is negative, the sentence asserts that $\mathrm{P}$ caused $\mathrm{Q}$.

b. If $\mathrm{P}$ has a stative sense, the sentence asserts that $\mathrm{P}$ caused $\mathrm{Q}$.

c. If $\mathrm{P}$ and $\mathrm{Q}$ share the same subject, $\mathrm{Q}$ is understood as temporally following $\mathrm{P}$, otherwise the sentence asserts that $\mathrm{P}$ caused $\mathrm{Q}$.

These conditions are largely successful at predicting which sense arises in a given sentence. For example, statement (2c) makes the correct predictions for the sentences in (1). That these two senses of -ese are really complementary, as captured by the conditional statements above, is supported by examples like the following (Lukoff and Nam 1982:563-564):
a. irena-se cel-ul ha-ss-ta
rise-ESE bow-ACC do-PST-DEC
'He got up and bowed.'
b. *irena-ci anh-ase cel-ul hay-ss-ta
rise-COMP NEG-ESE bow-ACC do-PST-DEC
'*Without getting up (first), he bowed.'
'*He did not get up and so he bowed.' (Implausible)
c. irena-ci anh-ko cel-ul hay-ss-ta rise-COMP NEG-KO bow-ACC do-PST-DEC 'He bowed without getting up (first).'

According to (2a), (3b) should have only the causal reading. That reading, however, is highly implausible in Korean culture. Nevertheless, a sequence reading is unavailable, even though as (3c), which uses the $-k o$ construction, shows that a reading as such is not implausible.

The characterization in (2), however, falls short for a number of reasons. First, as the authors themselves point out, there are a number of cases where the conditions make the wrong prediction. In the examples below, the $\mathrm{P}$ clause is neither negative nor stative, and $\mathrm{P}$ and $\mathrm{Q}$ have coreferential subjects, but the readings are causal (Lukoff and Nam 1982:569-570):

$$
\begin{aligned}
& \text { cha-eyse nayli-taka nemecye-se pyengwen-ey ka-ss-ta } \\
& \text { car-FROM descend-WHILE fall-ESE hospital-LOC go-PST-DEC } \\
& \text { 'He fell as he was getting out of the car and so he went to the hospital.' }
\end{aligned}
$$

ku-nal ku-ka ilccik cip-ey ka-se hwa-lul myon hay-ss-ta that-day he-NOM early home-LOC go-ESE disaster-ACC escape do-PST-DEC 'He escaped the disaster because he went home early that day.'

Although the conditions in (2) admit no such possibility, there are also cases where both readings are possible (Lukoff and Nam 1982:569): 


\section{Event Structure in Korean-ese Constructions}
hakkyo aph-eyse chulswu-lul
manna-se ku-yayki-lul hay-ss-ta school front-LOC Chulsu-ACC meet-ESE that-story-ACC do-PST-DEC 'I met Chulsu in front of the school and then told him about it.' 'I told Chulsu about it because I met him in front of the school.'

There are also cases where the P and Q clauses do not share the same subject, but the reading is sequential (Lukoff and Nam 1982:569):

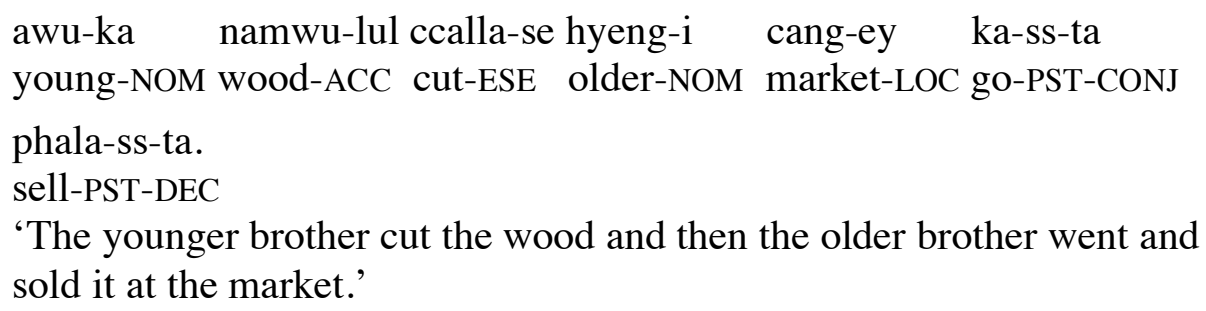

In addition to being unable to account for such exceptional cases, the conditions in (2) are incomplete in that the -ese construction exhibits further restrictions. For example, suppose a high school student goes to his room, opens the window, and then does his homework. This perfectly plausible sequence of events can be expressed in Korean with the -ko construction, but not with the -ese construction:

$$
\begin{aligned}
& \text { a. John-i changmwun-ul yel-ko swukcey-lul hay-ss-ta } \\
& \text { John-NOM window-ACC open-KO homework-ACC do-PST-DEC } \\
& \text { 'John opened the window and (then) did his homework.' } \\
& \text { b. *?John-i changmwun-ul yel-ese swukcey-lul hay-ss-ta } \\
& \text { John-NOM window-ACC open-ESE homework-ACC do-PST-DEC } \\
& \text { '*?John opened the window and (then) did his homework.' }
\end{aligned}
$$

As the examples above show, the approach represented by (2) is descriptively inadequate, and furthermore, unable even to give an indication as to how to make sense of the exceptional cases.

Thus, in the remainder of this paper, I present a cognitive-functional analysis of the semantics of -ese constructions based on Cognitive Grammar (Langacker 1991b), combining Langacker's verbal semantic model with Narayanan (1997)'s phased aspectual structure. This model predicts behavior deemed exceptional by earlier analyses and accounts for why sequential -ese cannot be used to connect just any pair of plausibly sequential events. It is able also to account for why given certain variations in the connected clauses, -ese constructions can also convey other relations, which have largely been ignored, such as temporal simultaneity, manner of motion, instrument, and means of causation. The analysis is further supported by the pattern of interaction between the various - ese constructions and progressivization. 


\title{
Jisup Hong
}

\section{Event Integration Model}

Cognitive Grammar models verbal predicates as processes, which are sequentially scanned complex temporal relations (Langacker 1991a,b). They are essentially conceptual models of how relations between participant entities change (or not) over time. The following diagrams, for example, represent the conceptually relevant facets of perfective and imperfective processes (Langacker 1991a:88):

Figure 1: Perfective and Imperfective Processes

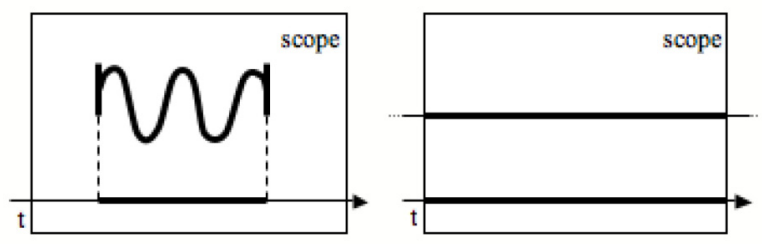

According to this model, the features that differentiate perfective and imperfective processes are temporal boundedness within the scope of predication and whether the relation is dynamic or static: perfective processes are temporally bounded and dynamic, while imperfective processes are temporally unbounded and homogenous.

In addition to the process model sketched above, I adopt an aspectual model in which certain processes may consist internally of discrete phases. Narayanan (1997) develops an aspectual model computed from the same structures needed for motor control systems. The general schema, as summarized in Lakoff and Johnson (1999:41), is as follows:

\author{
Getting into a state of readiness \\ The initial state \\ The starting process \\ The main process (either instantaneous or prolonged) \\ An option to stop \\ An option to resume \\ An option to iterate or continue the main process \\ A check to see if a goal has been met \\ The finishing process \\ The final state
}

Although the precise structure of specific processes will vary, the schema above allows for processes that occur as a series of phases, in which the main phase may be preceded by a preparatory phase or followed by a finishing phase.

\subsection{Sequential -ese}

Based on the framework described above, the semantics of -ese constructions can be modeled as a configuration of conceptual structures. In a sequence construal of a construction $P$-ese $Q$, I propose that the verbal process of the subordinate -ese clause $(\mathrm{P})$ is construed as the process-internal preparatory phase of the main 


\section{Event Structure in Korean-ese Constructions}

clause process $(\mathrm{Q})$, such that external to the scope of $\mathrm{Q}$, the resulting structure constitutes a single event. As shown diagrammatically in Figure 2, a consequential property of the integration is that process P's scope of predication must fit into Q's scope of predication and that process P's temporal profile is matched with start phase of process $\mathrm{Q}$.

Figure 2: Event Integration in Sequential -ese

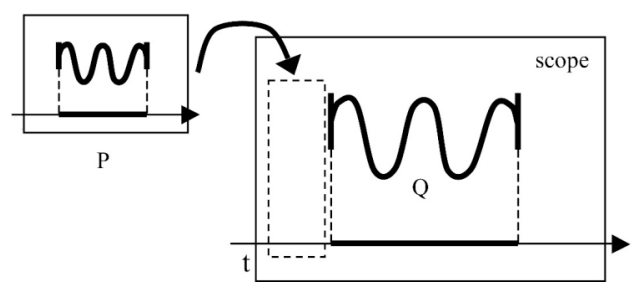

This model generates the following predictions for the behavior of sequential $P$ ese $Q$ constructions:

(9) a. Neither P nor Q may be imperfective.

b. Process $P$ cannot be negated.

c. Process P must share process Q's action chain.

With regard to (9a), the process Q cannot be imperfective, because, as depicted in Figure 2, an imperfective process, being unbounded within its predicational scope, does not have a preparatory or finishing phase to elaborate. Because the phases of a process must be perfective (otherwise, there would be no way to delineate their boundaries), the $\mathrm{P}$ clause cannot be imperfective either. Since a negated process profiles the non-occurrence or absence of a temporally profiled process, a negated predication is necessarily atemporal. Thus, such a process cannot be integrated with a necessarily bounded phase within another process.

Cognitive Grammar models the dynamic relations between participants of a process as a unidirectional chain of energy transfers from entity to entity, which is called an action chain (Langacker 1991a). Semantic roles, such as Agent and Patient, are construed relative to the action chain-e.g. the source of the energy is the Agent, and the sink is the Patient. The participants within a single process's scope of predication are structured according to one and only one action chain configuration. Thus, prediction (9c) arises because process P's scope must be contained within process Q's scope, as shown in Figure 2. Processes P and Q are predicated over a single action chain determined by the participant structure of $\mathrm{Q}$, and for process $\mathrm{P}$ to be integrated with the starting phase of process $\mathrm{Q}$, it must cohere with the conceptual structure evoked by process Q. Consequently, for example, if Q's action chain defines a participant $\mathrm{X}$ as the Agent, $\mathrm{P}$ cannot be construed with an action chain such that some other participant $\mathrm{Y}$ is the Agent. 


\section{Jisup Hong}

\subsection{Causal -ese}

When the integration represented by Figure 2 cannot apply, the sequential reading is unavailable, and conceptually there remain two distinct event predications, enabling a causal reading. For the causal sense, I propose that process $\mathrm{P}$ is related to process $\mathrm{Q}$ externally rather than internally. As such, the predicational scope of $\mathrm{P}$ is independent of Q's. The causal construal of P-ese $Q$ is modeled in this framework as a separately predicated event $\mathrm{P}$ that temporally precedes and causes the event Q.

Figure 3: Discrete Events in Causal -ese

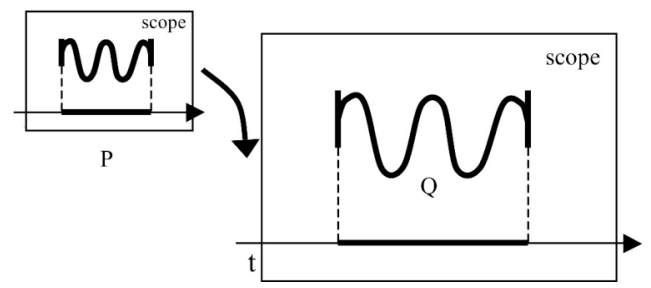

In the causal -ese construal, the $\mathrm{P}$ event is still subordinate to the $\mathrm{Q}$ event because only the $\mathrm{Q}$ event is grounded by tense or modality to the speech context. In addition to the temporal profiling of processes $\mathrm{P}$ and $\mathrm{Q}$, the Cause relation between them, represented by the bold arrow, is also profiled.

\subsection{Accounting for the Exceptional Cases}

The predictions generated by the event integration model shown in (9) and similar to, but not co-extensive with, Lukoff and Nam (1982)'s characterization in (2). The conditions in (9) predict and explain the exceptional cases presented in Section 1. Examples (4) - (5) have the causal reading because although the $\mathrm{P}$ and $\mathrm{Q}$ clauses share the same subject, they are not predicated over the same action chain. Because the verb in the P clause, nemeci-ta 'to fall,' is unaccusative, the subject of $\mathrm{P}$ is a Patient, i.e. the tail of its action chain. In contrast, the $\mathrm{Q}$ clause verb is transitive, and its subject is an Agent, i.e. the head of its action chain. Since the same entity cannot be both the head and the tail of the same action chain (except perhaps in reflexive predications), (4) fails condition (10c). The same analysis applies to (5) where situation is reversed-the verb in the P clause is transitive and the verb in Q clause is unaccusative. The verb myon ha-ta is better translated as 'to be exempted from,' where there is no implication of agency.

The multiple interpretation example in (6) is also straightforwardly explained. The verb manna-ta 'to meet' has two possible construals: in the first, the meeting event is deliberately orchestrated; in the second, the meeting is accidental. On the former reading, the subject of the P clause, identified contextually, is an Agent in both the $\mathrm{P}$ and $\mathrm{Q}$ clauses, thus allowing for the sequential reading of the sentence. In the latter case, the $\mathrm{P}$ clause subject is not agentive, but the same entity is agentive in the $\mathrm{Q}$ clause, allowing for the causal reading. 


\section{Event Structure in Korean-ese Constructions}

The counter-example in (7) was especially compelling because of its having different subjects and yet receiving the sequential reading. On the surface, this sentence would seem to contradict the predictions of (9) as well. The crucial difference, however, is that the cognitive-functional foundation of the event integration model provides a way to approach an explanation. I suggest that the sequential reading of (7) arises because the two brothers, the respective subjects of the two clauses, are construed as co-Agents. That is, the action chain over which (7) is predicated is unusual in having two energy sources - the configuration would thus, strictly, not be a chain, but a merging Y-shaped energy flow pattern, where the two starting chains converge at the wood that is being chopped and sold.

The earlier approaches were also too permissive in that they failed to exclude cases like (8b) where a possible sequence of events could not be expressed using an -ese construction. Some linguists, as in Kim (1994), propose that -ese expresses not mere sequences, but "necessary" sequences-that is, events which whenever they co-occur, they must occur in that sequence. Although empirically, the characterization merits testing, there is no explanation for how this condition relates to the others. By this approach, the specific behavior of -ese constructions seems to arise as a result of an arbitrary collection of unconnected properties.

The current approach, however, is able to provide a unified explanation of the patterns including (8b). This behavior is unsurprising for the present model because -ese is not modeled as a connector with the semantics "P precedes Q" but rather as a conceptualization where the process $\mathrm{P}$ is subsumed into the process $\mathrm{Q}$ as its start phase. Because the scope of predication, i.e. the evoked background, is determined by the $\mathrm{Q}$ clause, the properties of that background determine whether a $\mathrm{P}$ clause can be identified as a part of that background or not. Predications in Cognitive Grammar are not references to independently existing, objective relations in the world, but rather construed relations understood relative to gestalt conceptual structures, as in frame semantics (Fillmore 1982). In (8b), the opening of a window cannot be profiled as the start phase of doing homework because there is no role in the conventional doing-homework event structure to which a window, or the opening of a window, can be mapped. As to be expected, when speakers are primed with an unconventional doing-homework frame in which the student must open the window to measure the air temperature outside, the sequential reading becomes acceptable.

\section{Beyond Exceptional Cases}

It turns out, in fact, that -ese constructions can be used to convey more than just sequential or causal relations. The following are a number of additional types:

$$
\begin{aligned}
& \text { chayk-ul nwuwe-se ilk-ess-ta } \\
& \text { book-ACC lie-ESE read-PST-DEC } \\
& \text { 'I read the book lying down.' }
\end{aligned}
$$

[Temporal Simultaneity] 


\section{Jisup Hong}
(11) kelu-se haykyo-ey ka-ss-ta walk-ESE school-LOC go-PST-DEC '(He) went to school by walking'

[Manner of Motion]

[Instrumental]

(13) tol-ul tunce-se changmun-ul kkayttu-ly-ess-ta stone-ACC throw-ESE window-ACC break-CAUS-PST-DEC 'He threw a stone and broke a window (with it)' [Means of Causation]

Although earlier work has largely ignored these uses of -ese and provides no way of explaining if or how these relate to the sequential or causal uses, under the current model these readings can be straightforwardly accounted for as variations of the sequential event structure integration along parameters inherent to the conceptual structures.

\subsection{Temporal Simultaneity and Variations}

In the Temporal Simultaneity sense of the $P$-ese $Q$ construction, process $\mathrm{P}$ occurs simultaneously with process $\mathrm{Q}$. In some cases, there may also be the sense that the beginning of process $\mathrm{P}$ is before the beginning of process $\mathrm{Q}$. The semantics of this construction can be modeled as a variation of the sequential model where the process $\mathrm{P}$ is identified with the main phase of process $\mathrm{Q}$ instead of the starting phase. As is the case for sequential -ese, because process $\mathrm{P}$ is identified with a phase internal to process Q, it must share Q's predicational scope. However, two additional conditions must be met for such a construal: first, the temporal profile of P must be co-extensive with that of the temporal profile of Q's main phase; and secondly, it must be possible for both processes to occur simultaneously even while the processes share a single action chain.

In order for the first of these two conditions to be satisfied, I predict that the $\mathrm{P}$ process in simultaneous -ese constructions will be limited to a type of verb described in Langacker (1991a:93) as homogeneous but occurring in "bounded episodes." Such verbs in English include sleep, walk, and swim, which are dynamic but cyclical, or static but maintained. They are perfective in that they are bounded within the scope of predication, but because they are internally homogeneous, their temporal extension is flexible. In simultaneous -ese constructions, I propose that process $\mathrm{P}$ is construed as bound by the start and end states of the main phase of process $\mathrm{Q}$. Such homogeneous, bounded processes cannot be used as the preparatory process of sequential -ese constructions because they are, from an external point of view, atelic, resulting in no change of state.

Fulfillment of the second of the above conditions is dependent on the lexical semantics of the verbs in the $\mathrm{P}$ and $\mathrm{Q}$ clauses. This provides an explanation for the relatively narrow range of possibilities for such constructions. Most examples of 


\section{Event Structure in Korean-ese Constructions}

commonly encountered simultaneous -ese constructions involve posture verbs in the $\mathrm{P}$ clause. Such verbs are often construed with a telic starting phase in which the movement into the posture occurs, and a main phase in which the posture is maintained. In such cases, the integration can happen so that the telic start phase of $\mathrm{P}$ is identified with the start phase of $\mathrm{Q}$, and the maintained main phase of $\mathrm{P}$ is identified with the main phase of Q. This yields in the intuition mentioned earlier in which in some simultaneous -ese usages, the $\mathrm{P}$ process seemed to begin slightly prior to the $\mathrm{Q}$ process.

Manner of Motion -ese is a variation of simultaneous -ese where the P and Q clause verbs are related by what in Talmy (2000:49-57)'s typology of verb lexicalization patterns, is described as "Motion + Path" pattern, where the verb root expresses both Motion and Path, but Co-events, such as Manner, are encoded in a Satellite. Instrumental -ese is a variation of simultaneous -ese occurring in the limited case where the P clause verb is ssu-ta 'to use,' or synonymous to it.

Means of Causation is different from the other two variants in that the causative derivational suffix on the $\mathrm{Q}$ clause verb produces a process in which the end state is specified by the meaning of the root, but the main phase is underspecified as to how that end state is reached. The process is thus bounded but internally homogeneous, and differs from the typical simultaneous -ese construction in that the dynamic content - the means - is provided by the $\mathrm{P}$ clause process, rather than by the Q clause.

\section{Support from Progressive Formation}

The progressive is formed semantically by imposing an immediate scope of predication within the boundaries of a perfective process such that within that scope the process is construed homogeneously. This configuration is shown below (Langacker 1991a:92):

Figure 4: Progressive Aspect

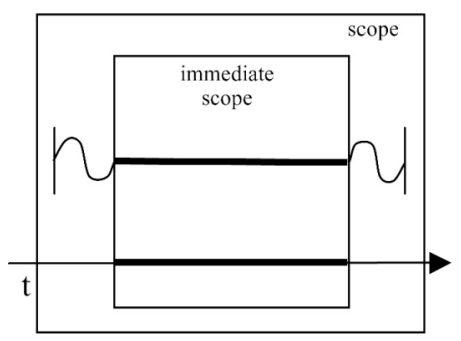

In Korean, the progressive is formed using a verbal suffix $-k o$ followed by the existential verb iss-ta. Adopting the approach in Narayanan (1997), I assume that progressive formation targets the main phase of the process. Based on this analysis of the progressive, the semantic interaction between -ese constructions and progressive formation is predicted by the model and variations presented in Sections 2 and 3. 


\section{Jisup Hong}

Progressive formation in the $\mathrm{P}$ clause essentially causes it to become imperfective-unbounded within its scope of predication and homogeneously construed. As such, progressivized $\mathrm{P}$ clauses are predicted not to occur with sequential -ese. This prediction is born out:

*John-i cip-ey ka-ko iss-ese kongpu hay-ss-ta John-NOM home-LOC go-PRG PRG-ESE study do-PST-DEC '*John is going home and then studied (there).'

Temporal Simultaneity, and the Manner of Motion and Instrumental, variations relied on having bounded but internally homogeneous processes in the P clause. Such processes occurred in "bounded episodes" and had flexible temporal extensions such that they could be made temporally co-extensive with the Q clause process's main phase. Applying the progressive would make them unbounded within the imposed scope of predication, destroying their ability to be matched up with a $\mathrm{Q}$ process's main phase. The Means of Causation -ese construction involved telic and perfective $\mathrm{P}$ clause processes, which would be rendered imperfective by progressivization. Thus, all the Temporal Simultaneity based senses are predicted to be incompatible with progressivized P clauses:

*chayk-ul nwue iss-ese ilk-ess-ta

book-ACC lie PRG-ESE read-PST-DEC

'*He read while he was lying down.'

*ttwi-ko iss-ese hakyo-ey ka-ss-ta run-PRG PRG-ESE school-LOC go-PST-DEC

'*He went to school by being running.'

*kempwute-lul ssu-ko iss-ese swukcey-lul hay-ss-ta computer-ACC use-PRG PRG-ESE homework-ACC do-PST-DEC '*He did his homework being using the computer.'

$$
\begin{aligned}
& \text { *tol-ul tunci-ko iss-ese changmwun-ul kkaythu-ly-ess-ta } \\
& \text { rock-ACC throw-PRG PRG-ESE window-ACC shatter-CAUS-PST-DEC } \\
& \text { '*He broke the window by being throwing a rock.' }
\end{aligned}
$$

Finally, the causal reading, which allows imperfective processes in its $\mathrm{P}$ clause, is predicted to allow progressivized $\mathrm{P}$ clauses. This prediction is also born out:

$$
\begin{array}{llll}
\text { cip-ey ka-ko iss-ese cyenhwa-lul an pat-na-pota } \\
\text { home-LOC go-PRG } & \text { PRG-ESE phone-ACC NEG receive-Q-CJTR } \\
\text { 'I guess he's not picking up because he's still on his way home.' }
\end{array}
$$




\section{Event Structure in Korean-ese Constructions}

The other set of possible constructions with progressive formation are those in which the $\mathrm{Q}$ clause has been progressivized. For sequential -ese, the present analysis predicts that the sequential meaning will be preserved and that the progressive semantics will target only the $\mathrm{Q}$ clause process. This is because the $\mathrm{P}$ clause is identified with the starting phase of the $\mathrm{Q}$ clause, while progressive formation targets the main phase of $\mathrm{Q}$. The following example fulfills these expectations:

$$
\begin{aligned}
& \text { John-i cip-ey ka-se kongpu ha-ko iss-ta } \\
& \text { John-NOM home-LOC go-ESE study do-PRG PRG-DEC } \\
& \text { 'John went home and is studying (there).' }
\end{aligned}
$$

In (20), it is understood that the trip home was completed, and that the subsequent studying is in progress.

For the Temporal Simultaneity based variations of -ese, however, the expectations are different. Because for these constructions the $\mathrm{P}$ clause event is coextensively matched with the main phase of the $\mathrm{Q}$ clause, the analysis predicts that progressive formation in the $\mathrm{Q}$ clause will target both processes. This prediction is born out in the following examples:

chayk-ul nwue-se ilk-ko iss-ta book-ACC lie-ESE read-PRG PRG-DEC

'He is reading while lying down.'

ttwi-ese hakyo-ey ka-ko iss-ta run-ESE school-LOC go-PRG PRG-DEC

'He is going to school by running.'

kempwute-lul ssu-ese swukcey-lul ha-ko iss-ta computer-ACC use-ESE homework-ACC do-PRG PRG-DEC 'He is doing homework using the computer.'

tol-ul tunci-ese changmwun-ul kkaythu-ly-ko iss-ta stone-ACC throw-ESE window-ACC shatter-CAUS-PRG PRG-DEC 'He is (in the middle of) breaking the window by throwing a stone.'

In each of the sentences above, both the $\mathrm{P}$ and the $\mathrm{Q}$ processes are understood as being in progress.

Finally, the present analysis predicts that the causal sense of -ese should be compatible with progressive formation in its Q clause:

paykopha-se ramyen-ul kkuli-ko iss-ess-ta hungry-ESE ramen-ACC boil-PRG PRG-PST-DEC 'He was making ramen because he was hungry.' 
Jisup Hong

\section{Conclusion}

In this paper, I presented a Cognitive Grammar analysis of Korean -ese, a multifunctional connective whose many uses were accounted for, descriptively and explanatorily, by models defined in terms of event integration. This approach was found to predict and explain behavior deemed exceptional and mysterious in previous treatments, as well as the existence and behavior of types of -ese constructions heretofore largely ignored. Finally, I presented further evidence in support of this model by examining how event integration interacts with the process of progressive formation. The success of this analysis is owed largely to the cognitively sophisticated theoretical framework from which it was developed.

\section{References}

Fillmore, Charles J. 1982. Frame semantics. In The Linguistic Society of Korea, ed., Linguistics in the morning calm, 111-137. Seoul: Hanshin Publishing Co.

Ihm, H.B., K. P. Hong, and S. I. Chang. 1988. Korean grammar for international learners. Seoul: Yonsei University Press.

Kim, Haeyeon. 1994. 'Speech act' adverbial clauses in Korean. In Y.K. KimRenaud, ed., Theoretical issues in Korean linguistics. Stanford, CA: CSLI.

Lakoff, George, and Mark Johnson. 1999. Philosophy in the flesh. New York: Basic Books.

Langacker, Ronald W. 1991a. Concept, image, and symbol. Berlin: Mouton de Gruyter.

Langacker, Ronald W. 1991b. Foundations of cognitive grammar, vol. 2. Stanford, CA: Stanford University Press.

Lee, Hansol H. B. 1989. Korean grammar. Oxford: Oxford University Press.

Lukoff, Fred, and Ki-Shim Nam. 1982. Constructions in -nikka and -ese as logical formulations. In The Linguistic Society of Korea, ed., Linguistics in the morning calm, 559-583. Seoul: Hanshin Publishing Company.

Narayanan, Srinivas S. 1997. Knowledge-based action representations for metaphor and aspect (KARMA). Ph.D. diss., University of California, Berkeley.

Rogers, Michael C., C. You, and K. K. Richards. 1992. College Korean. Berkeley, CA: University of California Press.

Talmy, Leonard. 2000. Toward a cognitive semantics: Typology and process in concept structuring, vol. 2. Cambridge, MA: MIT Press.

Jisup Hong

University of California, Berkeley

Department of Linguistics

1203 Dwinelle Hall

Berkeley, CA 94720-2650

jhong@berkeley.edu 